\title{
Scheduled Study Activity for Study Subject
}

National Cancer Institute

\section{Source}

National Cancer Institute. Scheduled Study Activity for Study Subject. NCI Thesaurus. Code C70712.

A state of an activity (such as a procedure, visit, examination, etc.), which has been assigned with the designation of a time or/and date when the activity has to be performed to a particular study subject according to the study protocol. 